\title{
Kindergarten area activity definition, system and significance ${ }^{1}$
}

\author{
Wang Yanjia ${ }^{1, a}$, Ren Jianhua ${ }^{2, b^{*}}$ \\ ${ }^{1}$ Education Department, Shihezi University, Shihezi, Xinjiang, P.R.China \\ ${ }^{2}$ Education Department, Shihezi University, Shihezi, Xinjiang, P.R.China \\ azjcrjy@126.com, 694024523@qq.cm ${ }^{\text {b }}$
}

Keywords: Kindergarten area activity; Kindergarten area activity practice system; Kindergarten area activity theory system.

\begin{abstract}
Rooted in Montessori Method, kindergarten area activity is one of the main child activities. It is the complementary activity for child concentrated teaching, gaming, and other basic child activities. It can compass rich contents, with broad and diverse forms. Based on the practice of kindergarten area activity and the past research on kindergarten area activity, We analyze and categorize kindergarten area activity and related concepts, aiming to provide a general description of the theoretical and practical systems of kindergarten area activity and to explore the functions of kindergarten area activity in child growth and development.
\end{abstract}

\section{Introduction}

Rooted in Montessori Method, kindergarten area activity is one of the main child activities. It is the complementary activity for child concentrated teaching, gaming, and other basic child activities. It can compass rich contents, with broad and diverse forms. Based on the practice of kindergarten area activity and the past research on kindergarten area activity, We analyze and categorize kindergarten area activity and related concepts, aiming to provide a general description of the theoretical and practical systems of kindergarten area activity and to explore the functions of kindergarten area activity in child growth and development.

\section{The definition and understanding of kindergarten area activity}

Considering the fact that the definition of kindergarten area activity is practical and is usually based upon its intrinsic meaning, we start with the definition used by He, Yangping (2010), Guo,Baofeng (2011) and Yang, Liyun (2012) in Preschool Education Research, Child Development Research and etc., analyze the most related originconcept to kindergarten area activity, and give a practical definition to kindergarten area activity.

The definition of kindergarten area activity. Educational environment is not the most related origin concept of kindergarten area activity. Zhang,Bo (2003) define area activities as activities occurred in the activity area, and the educational environment is where the activities take place. He define area activities as the purpose and meaning of these activities. Namely, area activities are activities designed by the teachers for the development of child interest and growth. They take place in certain educational environment, and in those activities, child can learn though proactive actions, promoting the comprehensive development of child physical and psychological development.

Learning activity is not the most related origin concept to kindergarten area activity. Yang, Lijun (2012) take proactive game and learning activities as the origin concept of kindergarten area activity. She uses autonomy and teacher's guidance as the limiting conditions to define area activities. She

\footnotetext{
${ }^{1}$ Wang Yanjia, a student of Education Department, Shihezi Uniersity, Shihezi, Xinjiang, P.R.China

${ }^{2}$ Corresponding author:Ren Jianhua, Pro, Education Department, Shihezi University, Shihezi, Xinjiang, P.R.China;
} 
suggests that kindergarten area activities are proactive game and learning activities in which child willingly choose, explore and manipulate. They are learning and gaming activities organized by teachers with different educational resources, allowing child to choose, cooperate, and explore with autonomy. This definition may confuse the relationship between kindergarten area activity and centralized teaching and the relationship between kindergarten area activity and gaming activity.

Educational activity is also not the most related origin concept to kindergarten area activity. Guo, Baofeng (2011) takes the educational activity as the origin concept of area activity, and uses activity basis, the design of activity areas, the autonomy of child, and teaher's guidance as limiting conditions to define area activities. She suggests that area activity is a type of educational activity. It is self-learning activity, self-exploring activity and interactive activity between the teacher and the child designed by teachers according to the teaching objective and the level of the child development .Both the activity environment and the activity materials are designed and provided to allow the child to manipulate the materials according to his own will and ability. It is correct to take educational activity as the origin concept of kindergarten area activity. However, it is not the most related origin concept.

We think that similar to child centralized teaching, child game and child basic life activity, kindergarten area activity belongs to educational activity, which is specifically related to child education and is practiced in a certain area. Compared with educational activities in middle school and elementary school, the subject, the object, the content, the method, the process, the objectives and the mission of kindergarten educational activity are unique because of the age of the children. Compared with child centralized teaching, child game and child life activity, the uniqueness of kindergarten area activity embodies in its purposefully designed area.

Therefore, we take the educational activity practiced in a certain activity area as the most related origin concept of kindergarten area activity. We use the subject, the object, the content, the method, the process, the objectives and the mission of this special educational activity as limiting conditions to define area activity. Namely, we define kindergarten area activity as a special educational activity taking place in certain activity area. More specifically, in such activity, teachers purposefully design areas with different purpose, different content, different forms, and different materials according to the development of the child and the aimed learning and development level. Based on the principle of autonomy, freedom and self-selection, the teacher can guide the child to practice and experience learning and development in the area of health, language, social, science and art. Child can gradually develop healthy personality and habit, and obtain comprehensive and harmonized development physically and psychologically.

The understanding of the concept of kindergarten regional activity . According to the definition of the concept of kindergarten regional activity, we believe that the special education activities of children, from the main, kindergarten regional activity object, basis, principle, method, carrier, purpose and significance in order to be understood.

The object of kindergarten regional activity is stipulated the infant stage of children education target experience and experience. At the present stage is mainly embodied in the "guidelines for kindergarten education", "the learning and development guidelines of 3-6 years old children" two files, reflect the implementation details and for carrying out the "guidelines for kindergarten education" and "the learning and development guidelines of 3-6 years old children" two files in various provinces and cities and counties, the practice also reflect regional activities in the each kindergarten according to the development characteristics of the formulation.

Kindergarten regional activity is based on the physical and mental development level of children, including the physical and psychological development level of children, the cognitive ability, emotional development, will quality even character development level, also includes a variety of material conditions to provide for children kindergarten regional activity. Also attaches great importance to the various critical development period the infant stage, in the critical period of the 
development of children in time for the child to provide for the active region of strong, so as to more effectively promote the growth and development of children.

Kindergarten regional activity carrier is the different form, different categories, different content, and different materials of the active region. Including children doll house, music, art, mathematics district district district science area, entertainment area and other activities area, activity area, activity area in computer science, natural activities outdoors sports zone, District, also includes a movable district culture, folk custom, ecological class. Considering the characteristics of the regional activities of the supplement, the kindergarten should pay attention to the regional activities and concentrated teaching activities, games, thematic activities integration, forming learning regional activities, the theme of regional activities and regional game activities, to improve the regional activities unique role in promoting the infant growth and development.

The principle of kindergarten regional activity is autonomy, freedom and self-selection . Autonomy refers to the children development level of independent choice of activity contents and activities in accordance with their partners. Freedom refers to the children pressure, let the children in the district where the activities activities in vivid, lively, active, happy. Optional refers to let every child can according to their interests, hobbies and needs to choose the activity content, materials and playmate. Independence, freedom and choice of property is the main features of regional activities, the main difference between children is also a sign of centralized teaching, games and other basic activities of life.

The methods of the kindergarten regional activity is that teachers guide children to operating various materials in the district activities, access to a variety of direct experience. In the free communication, so that children can enhance mutual understanding between peers, Academy of interactive and ways of communication.

\section{The theoretical system and practice system of kindergarten regional activity}

The theoretical system and practice system of kindergarten regional activity is the research object of kindergarten regional activity. The theoretical system of kindergarten regional activity is abstract reflect kindergarten regional activity practice, is the guiding ideology of kindergarten area activities. The practice system of regional activities in kindergarten is a kindergarten regional activity practice for a wide variety of child growth and development, the objective, is the source of the theory of kindergarten regional activity.

The theoretical system of kindergarten regional activity. The theoretical system of kindergarten regional activity including kindergarten regional activity concept, type, category, theory and thought, logic starting point of the theoretical system of the definition is made to kindergarten regional activity.

The concept of kindergarten regional activity, specific features include kindergarten regional activity in meaning and kindergarten regional activity main body, object, basis, principle, method, means, purpose and significance are shown, and kindergarten regional activity and focus on teaching activities, visit the links and differences between the drama activities, daily activities and theme activities.

The types of kindergarten regional activity are divided into two categories. In accordance with the mixed age attribute, attribute, attribute grade autonomy play, teachers' guidance and educators attribute seven attribute type is the main type kindergarten regional activity. Among them, the kindergarten mixed age attribute of regional activities can be divided into age of regional activities and regional activities of mixed age. Kindergarten grade attribute of regional activities can be divided into regional activities, small area PN activities, regional activities and regional activities of large class shift. The kindergarten play regional autonomy attributes of activities can be divided into autonomous regional activity and non autonomous regional activity. Kindergarten teachers guide the attribute of regional activities can be divided into guiding regional activity and non directive regional activity. Educators 
attribute kindergarten regional activity can be divided into the Montessori kindergarten regional activity, Hua Defu kindergarten regional activity and Chen Heqin kindergarten regional activity.

According to the learning field properties, equipment properties, indoor and outdoor attributes and shared property, the kindergarten regional activity object types can be divided into four types. Among them, the kindergarten learning field attribute of regional activities can be divided into health regional activities, language areas of activities, social activities, regional activities and regional science of kindergarten art activity in areas. The kindergarten indoor and outdoor attribute of regional activities can be divided into indoor and outdoor activity in areas of regional activities. Kindergarten shared attributes of regional activities can be divided into shared and non shared regional activities of regional activities.

Kindergarten regional activities areas include the subject and the object of kindergarten regional activities,levels and types of regional activities, kindergarten regional activity methods and tools as well as the purpose and significance.These four areas reflect the theoretical form which defines the concept of regional activities in the kindergarten class, but also the expansion of the concept of regional activities in the kindergarten, and consist of the logical starting point for kindergarten regional activity with the theory concept of kindergarten regional activities .

The theory of kindergarten regional activities includes philosophical theory, guiding theory, curriculum theory, management theory and psychological theory. Among them, the philosophical theory contains missions, values, culture and ecology concept of kindergarten regional activities, management theory contains the program and planning, leadership and management, performance and evaluation, and model and design, guiding theory includes guidance tasks, guiding principles to guide the process and so on.

The theoretical system of kindergarten regional activity. Practice system of kindergarten regional activities includes nursery management, implementation and research, practical system is the source of the theoretical system, also one of the basic ways to get kindergarten education task implementation. Taking the responsibility of the county-based preschool into account, the practical system includes leadership of regional activities, management of regional activities for kindergartens, the implementation of the regional activities for teachers.

Counties and cites mainly have program planning, financial support, education research and professional approach to lead, command, coordinate, supervise and evaluate for kindergarten regional activities. In accordance with the learning tasks and development objectives, combined with centralized teaching activities, games, daily living activities, the kindergarten will make plans, programs, so that teachers could implement regional activities. The practical subject for regional activities is teachers, they are designers, executors and administrators of setting regions, materials delivery, implementation of early childhood development and growth objectives, understanding children's interest in participating in regional activities and children autonomous choice.

\section{The role and significance of kindergarten regional activities}

Compared with centralized teaching and games in the kindergarten, regional activities to children in kindergarten activities autonomy, freedom and choice of features, make children operate and explore in health, language, social, scientific and artistic with their autonomy, freedom and choice, it has a unique role in promoting early childhood to coordinately develop in physical, intellectual, moral, and aesthetic.

The role and significance of kindergarten regional activities in child health development. Kindergarten regional activities play an important role in promoting and improving children's physical and mental condition, the habits and life skills . By participating in regional activities, children's body, emotions and adaptability could get exercise, so that making the physical and mental development. Meanwhile, children's balance, motor coordination and sensitive, strength and endurance as well as 
hand movements and flexible coordination could get exercise, so that making children action developed. By participating in regional activities, child life and health habits, basic living skills and basic knowledge of safety and self-protection capabilities can be improved, so that improving the children living habits and capacity.

The role and significance of kindergarten regional activities in child language development. Kindergarten regional activities have an important role in promoting and enhancing children's listening, speaking, reading and writing. By participating in regional activities, children could listen and understand the common language, be willing to communicate with others and articulate with a preliminary civilized language habits, so that children's listening and speaking ability can be improved. By participating in regional activities, children like to listen to stories, read books with an initial desire to reading comprehension and writing skills as well as improving early childhood reading and writing preparation.

The role and significance of kindergarten regional activities in child social development. Kindergarten regional activities play an important role in promoting and enhancing social adaptability for children. By participating in regional activities, children are happy with people, able to get along with their peers, have self-esteem, self-confidence, self-respect and concern for the performance of others, so that children develop their interpersonal skills. By participating in regional activities, children gradually adapt to community life and love it, comply with the basic norms of the target and have a preliminary sense of belonging, social adaptability.

The role and significance of kindergarten regional activities in child science development. Kindergarten regional activities plays an important role in the promotion of scientific inquiry, toddlers mathematical cognition. By participating in regional activities, children are closed to nature, like to explore, have a preliminary inquiry and the ability to recognize things around. By participating in regional activities, children could have the initial perception of the usefulness of mathematics and taste, perception and understanding of the number, volume, numbers of relationships, the shape and spatial relationships, contributing to develop children's mathematics cognitive abilities.

The role and significance of kindergarten regional activities in child art development. Kindergarten regional activities have an important role in promoting and improving early childhood feelings and appreciation of art, artistic expression and creation. By participating in regional activities, children love the nature and the living things in the world, like to enjoy a wide varieties of art forms, so that the ability of feeling and appreciation for children could be developed. By participating in regional activities, children begin to enjoy artistic activities and bold performance, have the initial artistic expression and creativity, artistic expression, creativity of young children could be developed.

\section{References}

[1] ZhangBo.Research of modern early childhood education[M].Changchun:Northeast Normal University Press,2003:97.

[2] HeYanping.Practice and exploration of kindergarten area activities[M].Beijing:Beijing Normal University Press, 2010:6.

[3] GuoBaofeng,LiZhiying.Analysis of problems and solutions of kindergarten regional activities[J].Research of children development,2011, 02:35-37.

[4] YangLijun,DengShuang.Effectiveness of model kindergarten regional activity material[J].Preschool study,2012,05: 44-47.

[5] Xiaoyan Wu. Through a scientific way of preschool education. Beijing: China Land Press, 2002.

[6] Maria Montessori. The secret of childhood. Beijing: Jinghua Publishing House,2002 
[7] Lin Lin. see the world from artist's sight -on kid's art aesthetic appraisal ability development. Preschool Education. 2004,(01) :18..

[8] Douglas H.Clements. The review of calculator with young child research. http://www.hoing.net/show.php

??id=331.

[9] Haixia Deng. On children's art education. Journal of Xinjiang Oil Education College, 2001, (4)

[10] Gecheng Huang. The function of multimedia in children education. Preschool Education, 2000 (1) 